\title{
Erratum to: Student-directed retrieval practice is a predictor of medical licensing examination performance
}

\author{
Francis Deng ${ }^{1}$ Jeffrey A. Gluckstein ${ }^{1}$ Douglas P. Larsen ${ }^{2}$
}

Published online: 18 November 2016

(C) The Author(s) 2016. This article is available at SpringerLink with Open Access.

\section{Erratum to:}

Perspect Med Educ (2015) 4:308-313

DOI 10.1007/s40037-015-0220-x

In the version of the article originally published online, there was an error in Table 3 (page 312). The B coefficient for the variable "Anki" should be $5.89 \times 10^{-4}$ rather than $5.89 \times 10^{-3}$. The exponent is correctly reported in the body text (page 311).
Open Access This article is distributed under the terms of the Creative Commons Attribution 4.0 International License (http:// creativecommons.org/licenses/by/4.0/), which permits unrestricted use, distribution, and reproduction in any medium, provided you give appropriate credit to the original author(s) and the source, provide a link to the Creative Commons license, and indicate if changes were made.

The online version of the original article can be found under http://dx.doi.org/10.1007/s40037-015-0220-x.

$\triangle$ Francis Deng

francisdeng@wustl.edu

1 Brigham and Women's Hospital, Harvard Medical School, 75 Francis St, Boston, MA 02115, USA

2 Department of Neurology, Washington University School of Medicine, Saint Louis, MO, USA 